\title{
Seroprevalence of Toxoplasma gondii infection in feral cats in Qatar
}

\author{
Sonia Boughattas', Jerzy Behnke², Aarti Sharma ${ }^{1}$ and Marawan Abu-Madi*
}

\begin{abstract}
Background: Cats are essential in the life cycle of Toxoplasma gondii as they can shed the environmentally resistant oocysts after acquiring infection. Human populations living in cities with high densities of feral cats are therefore likely to be at risk of infection. The current study is the first to estimate the seroprevalence of $T$. gondii in the feral cat population in Qatar. We investigated the seroprevalence of T. gondii among 495 adult cats from urban and suburban districts in Qatar. Using results from the Modified Agglutination Test, we fitted statistical models with host sex, area and season as explanatory factors and seropositivity as the outcome.

Results: The analysis revealed an overall seroprevalence of $82 \%$. Seroprevalence was significantly higher in the summer season $(P=0.006)$. No significant difference was detected $(P>0.05)$ between seroprevalence in female and male cats and in cats from urban and suburban districts of Qatar.

Conclusions: Despite the seasonal difference, the observed seroprevalence of T. gondii suggests high environmental contamination throughout the year, with some female cats generating more intense responses compared to males. Both findings merit further investigations.
\end{abstract}

Keywords: Serosurvey, Antibodies, Toxoplasmosis, Felids, Middle East, Season, Sex

\section{Background}

Toxoplasmosis is a widespread zoonotic parasitic infection. It is estimated that about one third of the world population is chronically infected with Toxoplasma gondii.

Felids are the only definitive hosts of the parasite and can shed millions of environmentally resistant oocysts in their feces if they become infected [1]. The oocysts can remain infectious for more than 1 year in unfrozen and moist soil [2] and can cause outbreaks of toxoplasmosis. This is evidenced by the large waterborne outbreak of toxoplasmosis in Canada in 1995 that was epidemiologically linked to oocyst contamination of a water reservoir in British Columbia [3].

Cats were introduced to Qatar in the 1960s to control the high rodent population in the country, but subsequently they in turn reproduced rapidly [4]. The current density of cats in Qatar may pose a risk for humans, as cats are natural hosts for a wide range of zoonotic pathogens, including $T$. gondii. The overall seroprevalence of

\footnotetext{
*Correspondence: abumadi@qu.edu.qa

${ }^{1}$ Department of Biomedical Science, College of Health Sciences, Biomedical

Research Center, Qatar University, P.O. Box 2713, Doha, Qatar

Full list of author information is available at the end of the article
}

T. gondii among the Qatari human population has been estimated at $29.8 \%$ with a progressive rise from $<4 \%$ in the 1 year old group to $41.2 \%$ at $>45$ years of age [5]. Such observations provide further evidence for the increased risk of infection with increasing age through longer exposure time.

As cats shed Toxoplasma oocysts for only a short period of time after initial infection, detection of patent infections in cat populations (based on faecal oocyst counts) is likely to underestimate the number of animals that have been exposed to infection [1]. However, T. gondii elicits strong antibody responses in its hosts and therefore assessment of seroprevalence is an alternative approach for studying the epidemiology of this pathogen. Estimates of antibody prevalence in the cat population also provide another useful indicator of environmental contamination [6]. The current study is the first to estimate the seroprevalence of $T$. gondii in the feral cat population in Qatar.

\section{Methods}

\section{Sample collection}

Feral cats were caught live as part of the routine activities of the Qatar Cat Control Unit as described previously [4]. 
Briefly, trapped adult cats that were eligible for the trap-neuter-return program were transported to a shelter for sterilization. For each animal the sex, the area, and the season of sampling were recorded. In the current study, sampling began in September 2014, and ended in September 2015 (394 samples in summer and 101 samples in winter).

Cats from both urban $(n=216)$ and sub-urban $(n=279)$ areas were investigated in this study. Within each sector, traps were set out in places most likely to be frequented by cats at night, i.e. in alleyways, in back yards close to houses, and near to rubbish bins and municipal garbage containers.

Blood was drawn by experienced veterinarians complying strictly with animal welfare guidelines as stipulated by the National Institutional Animal Care and Use Committee of Qatar. Blood samples were then centrifuged at $5000 \times g$ for $20 \mathrm{~min}$ at room temperature and the resulting supernatants were collected and used for serology.

\section{Serology}

A total number of 495 sera (234 males and 261 females) were tested for $T$. gondii IgG antibodies using commercially available Toxoplasma gondii antigen (\#EH2001, Kerafast $^{\oplus}$ Boston, USA). Two-fold serial dilutions, in phosphate buffered saline $(\mathrm{pH} 7.2)$, were made from 1:25 to $1: 200$ and tested with a Modified Agglutination Test (MAT), as previously described [7]. Samples that were positive at a dilution of 1:200 were further diluted in a second run to a dilution of 1:3,200 for antibody titration, and those positive at 1:3,200 were diluted in a third run until no further agglutination was evident.

Positive controls (provided by the Department of Laboratory Medicine and Pathology at Hamad General Hospital) and negative controls (serum dilution buffer without serum) were included in each test. Agglutination in at least half of the " $U$ " well bottoms of a microplate was accepted as a positive reaction. In the case of complete sedimentation on the well bottom with no sign of agglutination, the sample was recorded as negative, i.e. no evidence of $T$. gondii antibodies in the serum. A titer (inverse of a dilution) of 25 or higher was considered positive.

\section{Statistical analysis}

Prevalence values (percentage of animals infected) are given with 95\% confidence limits (CL95), calculated by bespoke software based on the tables of Rohlf and Sokal [8]. For analysis of seroprevalence, we used maximum likelihood techniques based on log linear analysis of contingency tables in the software package IBM SPSS Statistics Version 21 (IBM Corporation). Initially, full factorial models were fitted, incorporating as factors SEX (at 2 levels, males and females), AREA (at 2 levels, 1 for urban areas [Al Hilal, Bin Omran, Al Sadd, Umm-Ghwailina,
Al Salata, Madinat Khalifa, Al Nasr, Al Maamoura, Al Dafna, Al Muntzah, Al Markhiya, Al Najma, Old Airport, $\mathrm{Al}$ Asiri] and 2 for suburban areas [Al Azizia, Al Rayyan, Al Luqta, Al Waab, Abu Hamour, Al Wakrah, Muaither, Um Al Amad, Shahaniya, Al Gharrafa, Al Kharaitiyat, Umm Salal, Al Zaghwa, Al Wajba, Al Khor, Al Khissa]) and SEASON (at 2 levels, summer [May-October] and winter [November-April]). INFECTION, reflecting the presence or absence of antibodies to $T$. gondii (overall or at specific dilutions) was coded as a binary factor, and the cut-off for statistical significance was considered to be a $P$ value of 0.05 (two tailed) [4].

For analysis of quantitative data we first ranked the titers on a scale from 0 to 8 , where $0=$ no agglutination, 1 $=$ maximum agglutination at 1:25 and so on to $8=$ agglutination at dilutions higher than 1:3,200. We used a zeroinflated model in $\mathrm{R}$ version 2.2.1 ( $\mathrm{R}$ Core Development Team and the pscl package) that analyzed a binomial process $(0,1$ for the high responders versus the rest with a binomial model with logit link) and a Poisson (Poisson model with log link) for the rest.

\section{Results}

Of the 495 feral cats (234 males and 261 females) tested, 406 (82.0\%, CL $\left._{95}=76.11-86.79\right)$ were positive for $T$. gondii antibodies. Four samples presented prozone effects with negative results at the low dilution of 1:25 and positive agglutination at higher dilutions $\geq 1: 1,600$. The frequency distribution of antibody titers among the sampled cats is shown in Fig. 1, and the bimodal distribution of antibody titres, with peaks in the lower and top ends of the positive range can be clearly seen.

Seroprevalence of $T$. gondii was similar in males and females: $82.5 \%\left(\mathrm{CL}_{95}=78.58-85.84\right)$ and $81.6 \%$ $\left(\mathrm{CL}_{95}=77.45-85.17\right)$ respectively. With SEASON and AREA taken into account, the difference between the sexes was not significant (for SEX $\mathrm{x}$ INFECTION $\chi_{1}^{2}$ $=0.216, P>0.05)$. However, when the prevalence of antibodies in male and female cats was plotted separately against serum dilution (Fig. 2a), there was a significant effect of host SEX at high antibody titers (models taking SEASON and AREA taken into consideration, at a serum dilution of $1: 400$, for SEX $x$ INFECTION $\chi_{1}^{2}=$ 11.69, $P=0.001$; and in serum dilutions higher than 1:3,200; $\left.\chi_{1}^{2}=7.30, P=0.007\right)$.

Seroprevalence was similar in cats from urban and sub-urban areas $\left(82.4 \%, \mathrm{CL}_{95}=78.64-85.67\right.$, and $81.7 \%$, $\mathrm{CL}_{95}=77.42-85.37$, respectively) and no significant difference between areas was detected whether testing overall positivity (for AREA $x$ INFECTION $\chi_{1}^{2}=0.42$, $P>0.05$ ), or positivity at specific dilutions of serum.

The number of cats sampled in the summer was 394, and 101 in the winter months. There was a significant effect of SEASON on seropositivity (with host SEX and 


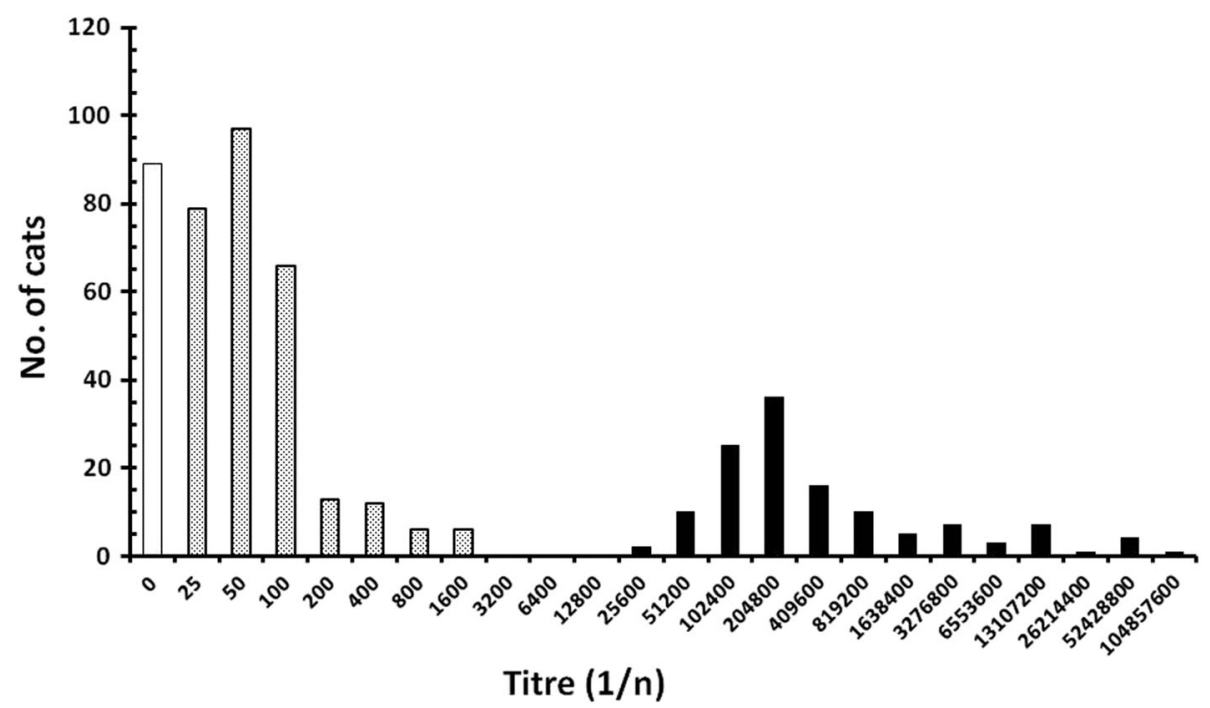

Fig. 1 Frequency distribution of antibody titres among the sampled cats. The figure shows the number of cats for which no antibody was detected (first column filled in white) and those that had detectable antibody. Titres for the latter are given as the reciprocal of the maximum dilution (n) at which agglutination was detected and these fall into two peaks. Columns filled with stippled shading indicate the numbers of cats with titres in the lower intensity antibody range and those filled in black represent cats with the higher titres

AREA taken into account, for SEASON $x$ INFECTION $\left.X_{1}^{2}=7.52, P=0.006\right)$. Seroprevalence was higher in the summer months $\left(84.5 \%, \mathrm{CL}_{95}=79.62-88.46\right)$ in contrast to the winter $\left(72.3 \%, \mathrm{CL}_{95}=65.53-78.14\right.$ and see Fig. $\left.2 \mathrm{~b}\right)$.

Quantitative analysis was in general in agreement with these conclusions. Based on the zero-inflated model and a binomial process in which the high responders (cats showing titers in excess of 1:3,200) were coded as 1 , and the rest as zero, the occurrence of the highest titers $(>1: 3,200)$ was affected significantly only by host sex $(z=2.534, \quad P=0.0113)$. Males (mean rank $=0.201 \pm$ $0.025, n=234)$ had a lower frequency of high titers than females (mean rank $=0.307 \pm 0.029, n=251$ ), as found in the earlier log linear model given above.

\section{Discussion}

This study demonstrated a high overall seroprevalence of $T$. gondii antibodies in the feral cat population in Qatar. Seroprevalence was higher than values reported from neighboring countries, as for example $19.6 \%$ in Kuwait [9] and $30.4 \%$ in Iraq [10]. Similar seroprevalences to those recorded in this study have been observed mainly among cats from tropical areas: Ethiopia with 85.4\% [11] and the Amazon with 87.3\% [12].

While the present work did not find an overall significant difference in seroprevalence between male and female cats as observed elsewhere [13, 14], higher antibody titers were detected in female cats when analysis was restricted to the high dilutions $(>1 / 400)$ which is in accordance with other reports $[6,15]$. However our observation of some female cats expressing more intense antibody responses than male cats contrasts with the conclusions reached by Miro et al. [16], who reported in their study that stray male cats had significantly higher seroprevalence. The authors linked their findings to differences in the territorial habits of male and female cats, as male cats are more likely to wander and thus experience more access to contaminated sources [17]. Although ecological, social and epidemiological factors may account for some of the female biased antibody responses in our study, hormone-influenced immunological mechanisms have been proposed as the more likely mechanism underlying sex-biased parasitism with $T$. gondii [18].

Cat bioassays have not provided any clear evidence of sex-bias in the occurrence of toxoplasmosis [19]. However, experimental studies in mice have shown that females are more susceptible than males to $T$. gondii infection and develop more severe cerebral inflammation. They are more likely to die following infection than males [20]. Female mice that survived the acute phase and developed chronic infections harbored more cysts in their brains than did surviving males. Gonadectomy of female mice was shown to reduce the development of tissue cysts caused by $T$. gondii infection, whereas estrogen administration was found to exacerbate the infection [21].

It remains unknown when the cats that tested positive had acquired the infection. The low intensity responses $(\leq 1 / 400)$ which were recorded in more than half of the cats in our study suggest antibodies from a past infection but may also include cats that have very recently been exposed to the parasite, and have not yet developed 


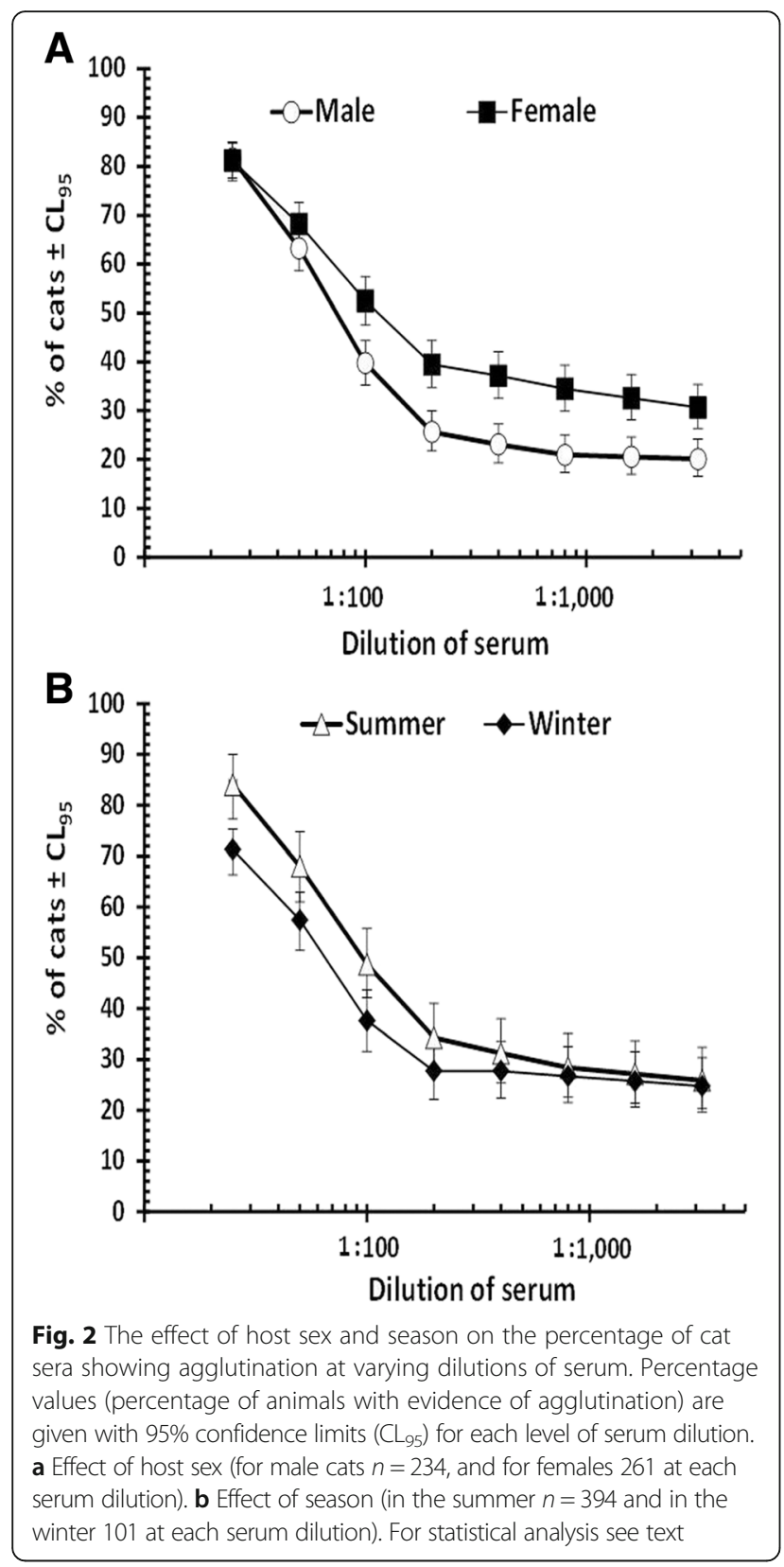

the maximum response. The cats that showed intense antibody responses ( $\geq 1 / 800$ dilution) are more likely to be cats that had acquired the infection recently but after a sufficient time to mount the response [22]. Since the prevalence of high intensity antibody responses was almost identical in both winter and summer months, this indicates that there is a persistent source of T. gondii infection in the environment in which the cats live. Moreover, the consistently high seroprevalence in both urban and sub-urban areas of Qatar suggests a high level of $T$. gondii contamination throughout the country.

The large home ranges of feral cats, which can stretch to $10 \mathrm{~km}^{2}$, implies widespread contamination of the environment, especially given that some reports have documented cats travelling up to $45 \mathrm{~km}$ in just 2 days [23]. Domestic and stray/feral cats are the same species (Felis catus) and the main difference between them is their lifestyle. In contrast to domestic animals, feral cats are unowned and live in the streets, alleys, farm buildings, factories, wharves or abandoned vehicles. They may be semi dependent on humans from whom they may receive some food. It has been reported elsewhere that $76.5 \%$ of cats fed table leftovers are Toxoplasma seropositive with a majority showing high IgG antibodies titers [24]. These free-roaming cats are exposed to a wide variety of pathogens, and have been shown to be excellent sentinels of infectious and parasitic diseases. Consequently they provide useful information on circulation of pathogens in domestic and wild ecosystems [13]. Most cats are thought to become infected with $T$. gondii after weaning when they begin to hunt for food. Outdoor access facilitates hunting behavior, as in the Netherlands where $93 \%$ of the cats with free outdoor access exhibited hunting behavior [22]. Stray cats and cats with outdoor access usually acquire the infection from hunting rather than from the ingestion of oocysts [25]. Hence the recommendation to pet owners that to protect their cats from $T$. gondii infection the hunting of small prey should be discouraged/prevented, and that all meat served to their pet cats should be thoroughly cooked and/or frozen before cooking [26].

In a study conducted in Italy, it was suggested that infected intermediate hosts that are prey for cats are more available in the summer season [27]. A recent analysis reported a correlation between the geolatitude (which strongly correlates with temperature and quantity and quality of sunlight) and humidity (which favors the survival of Toxoplasma oocysts in soil) and occurrence of toxoplasmosis [28]. The efficiency of transmission may therefore differ between seasons in Qatar, with a higher risk of exposure in the summer months (where the climate is more suitable for survival of the oocysts). Qatar typically experiences two seasons. In the summer season, daytime temperatures frequently exceed $45{ }^{\circ} \mathrm{C}$ and seldom fall below $18{ }^{\circ} \mathrm{C}$ at night. Humidity peaks in August at $90 \%$, before subsiding to $70 \%$ towards the end of October [4]. The latter months of the summer season certainly fall within this definition of the optimal climatic conditions for transmission. During the winter season temperatures peak at about $28{ }^{\circ} \mathrm{C}$ and may fall as low as $7{ }^{\circ} \mathrm{C}$ at night and the mean humidity is usually in the range $75-86 \%$. These conditions are less suitable for survival of oocysts of $T$. gondii in the external environment. Thus, the tenacity and infectivity of oocysts in winter may be less than in summer, and hence transmission to cats and potential intermediate hosts such as rodents may be less efficient in winter months. However, this 
requires further studies, for instance by environmental sampling for $T$. gondii oocysts and thorough assessment of the resilience of oocysts of local isolates of $T$. gondii to typical summer and winter conditions in Qatar. Unfortunately, most people are unaware that they can acquire toxoplasmosis from the environment by direct contact with soil or water [29].

\section{Conclusions}

The seroprevalence of T.gondii in cats in Qatar is high. Our data showed that female cats were more likely to have high antibody responses compared with males, and that seroprevalence is higher in the summer months. Overall, our data imply high contamination of the local environment in Qatar and we recommend further investigation of food/ water sources through which transmission may occur.

\section{Acknowledgments}

We would like to thank the Biomedical Research Center at Qatar University and the Cat Control Unit at the Ministry of Municipality and Environment for providing facilities for this work.

\section{Funding}

This publication was made possible by NPRP grant number NPRP 4-164-4001 from Qatar National Research Fund. The contents of this report are solely the responsibility of the authors and do not necessarily represent the official views of Qatar University and QRNF.

\section{Availability of data and materials}

Data will not be made available. We were constrained by our local, internal ethics policies, which entail confidentiality with regard to the samples for analysis in studies of this nature. We tried to put all the information needed for understanding the analysis and the subsequent results into the Methods section.

\section{Authors' contributions}

SB carried out the serology and drafted the manuscript. AS collected the cat samples and contributed to the serology. JMB carried out the statistical analysis and participated in the preparation and refinement of the manuscript. MAM conceived the study, collected the background information on the samples and revised the manuscript critically for important intellectual content. All authors read and approved the final manuscript.

\section{Competing interests}

The authors declare that they have no competing interests.

\section{Consent for publication}

Not applicable.

\section{Ethics approval}

All applicable institutional and/or national guidelines for the care and use of animals were followed. Ethical approval for this project was obtained from Qatar University Institutional Animal Care and Use Committee (Research Ethics Approval \# QU-IACUC 022/2015).

\section{Author details}

${ }^{1}$ Department of Biomedical Science, College of Health Sciences, Biomedical Research Center, Qatar University, P.O. Box 2713, Doha, Qatar. ${ }^{2}$ School of Biology, University of Nottingham, University Park, Nottingham NG7 2RD, UK.

Received: 15 July 2016 Accepted: 13 January 2017

Published online: 18 January 2017

\section{References}

1. Dubey JP. Oocyst shedding by cats fed isolated bradyzoites and comparison of infectivity of bradyzoites of the VEG strain Toxoplasma gondii to cats and mice. J Parasitol. 2001;87:215-9.
2. Mancianti F, Nardoni S, Mugnaini L, Zambernardi L, Guerrini A, Gazzola V, Papini RA. A retrospective molecular study of select intestinal protozoa in healthy pet cats from Italy. J Feline Med Surg. 2015;17:163-7.

3. Bowie WR, King AS, Werker DH, Isaac-Renton JL, Bell A, Eng SB, Marion SA Outbreak of toxoplasmosis associated with municipal drinking water. The BC Toxoplasma Investigation Team. Lancet. 1997;350:173-7.

4. Abu-Madi MA, Behnke JM. Feline patent Toxoplasma-like coccidiosis among feral cats (Felis catus) in Doha city, Qatar and its immediate surroundings. Acta Parasitol. 2014;59:390-7.

5. Abu-Madi MA, Al-Molawi N, Behnke JM. Seroprevalence and epidemiological correlates of Toxoplasma gondii infections among patients referred for hospital-based serological testing in Doha, Qatar. Parasit Vectors. 2008;1:39.

6. Silaghi C, Knaus M, Rapti D, Kusi I, Shukullari E, Hamel D, Pfister K, Rehbein S. Survey of Toxoplasma gondii and Neospora caninum, haemotropic mycoplasmas and other arthropod-borne pathogens in cats from Albania. Parasit Vectors. 2014;7:62.

7. Dubey JP, Desmonts G. Serological responses of equids fed Toxoplasma gondii oocysts. Equine Vet J. 1987;19:337-9.

8. Rohlf FJ, Sokal RR. Statistical Tables (3rd Edition) W.H. Freeman and Company, San Francisco 1995.

9. Abdou NE, Al-Batel MK, El-Azazy OM, Sami AM, Majeed QA. Enteric protozoan parasites in stray cats in Kuwait with special references to toxoplasmosis and risk factors affecting its occurrence. J Egypt Soc Parasitol. 2013;43:303-14.

10. Switzer AD, McMillan-Cole AC, Kasten RW, Stuckey MJ, Kass PH, Chomel BB. Bartonella and Toxoplasma infections in stray cats from Iraq. Am J Trop Med Hyg. 2013:89:1219-24.

11. Tiao N, Darrington C, Molla B, Saville WJ, Tilahun G, Kwok OC, Gebreyes WA, Lappin MR, Jones JL, Dubey JP. An investigation into the seroprevalence of Toxoplasma gondii, Bartonella spp., feline immunodeficiency virus (FIV), and feline leukaemia virus (FeLV) in cats in Addis Ababa, Ethiopia. Epidemiol Infect. 2013; 141: 1029-33.

12. Cavalcante GT, Aguiar DM, Chiebao D, Dubey JP, Ruiz VL, Dias RA, Camargo LM, Labruna MB, Gennari SM. Seroprevalence of Toxoplasma gondii antibodies in cats and pigs from rural Western Amazon, Brazil. J Parasitol. 2006;92:863-4.

13. Adams PJ, Elliot AD, Algar D, Brazell RI. Gastrointestinal parasites of feral cats from Christmas Island. Aust Vet J. 2008;86:60-3.

14. Cong W, Meng QF, Blaga R, Villena I, Zhu XQ, Qian AD. Toxoplasma gondii, Dirofilaria immitis, feline immunodeficiency virus (FIV), and feline leukemia virus (FeLV) infections in stray and pet cats (Felis catus) in northwest China: co-infections and risk factors. Parasitol Res. 2016;115:217-23.

15. Jittapalapong S, Nimsupan B, Pinyopanuwat N, Chimnoi W, Kabeya H, Maruyama S. Seroprevalence of Toxoplasma gondii antibodies in stray cats and dogs in the Bangkok metropolitan area, Thailand. Vet Parasitol. 2007; 145:138-41.

16. Miro G, Montoya A, Jimenez S, Frisuelos C, Mateo M, Fuentes I. Prevalence of antibodies to Toxoplasma gondii and intestinal parasites in stray, farm and household cats in Spain. Vet Parasitol. 2004;126:249-55.

17. Rahimi MT, Daryani A, Sarvi S, Shokri A, Ahmadpour E, Teshnizi SH, Mizani A, Sharif M. Cats and Toxoplasma gondii: A systematic review and meta-analysis in Iran. Onderstepoort J Vet Res. 2015;82:823.

18. Flegr J, Lindova JL, Kodym P. Sex-dependent toxoplasmosis associated differences in testosterone concentration in humans. Parasitology. 2008;135: 427-31.

19. Dubey JP, Hoover EA, Walls KW. Effect of age and sex on the acquisition of immunity to toxoplasmosis in cats. J Protozool. 1977;24:184-6.

20. Klein SL. Hormonal and immunological mechanisms mediating sex differences in parasite infection. Parasite Immunol. 2004;26:246-64.

21. Roberts CW, Cruickshank SM, Alexander J. Sex-determined resistance to Toxoplasma gondii is associated with temporal differences in cytokine production. Infect Immun. 1995;63:2549-55.

22. Opsteegh M, Haveman R, Swart AN, Mensink-Beerepoot ME, Hofhuis A, Langelaar MF, van der Giessen JW. Seroprevalence and risk factors for Toxoplasma gondii infection in domestic cats in The Netherlands. Prev Vet Med. 2012;104:317-26

23. Fancourt BA, Jackson RB. Regional seroprevalence of Toxoplasma gondii antibodies in feral and stray cats (Felis catus) from Tasmania. Aust J Zool. 2014:62:272-83.

24. Galván Ramírez ML, Sánchez Vargas G, Vielma Sandoval M, Soto Mancilla JL. Presence of anti-Toxoplasma antibodies in humans and their cats in the urban zone of Guadalajara. Rev Soc Bras Med Trop. 1999;32:483-8. 
25. Deksne G, Petrusēviča A, Kirjušina M. Seroprevalence and factors associated with Toxoplasma gondii infection in domestic cats from urban areas in Latvia. J Parasitol. 2013;99:48-50.

26. Jokelainen $P$, Simola O, Rantanen E, Näreaho A, Lohi H, Sukura A. Feline toxoplasmosis in Finland: cross-sectional epidemiological study and case series study. J Vet Diagn Invest. 2012;24:1115-24.

27. Papini R, Sbrana C, Rosa B, Saturni AM, Sorrentino AM, Cerretani M, Raffaelli G, Guidi G. Serological survey of Toxoplasma gondii infections in stray cats from Italy. Rev Med Vet. 2006;157:193-6.

28. Flegr J, Prandota J, Sovičková M, Israili ZH. Toxoplasmosis - A Global Threat. Correlation of latent toxoplasmosis with specific disease burden in a set of 88 countries. PLoS One. 2014;9:e90203.

29. Torrey EF, Yolken RH. Toxoplasma oocysts as a public health problem. Trends Parasitol. 2013;29:380-4.

Submit your next manuscript to BioMed Central and we will help you at every step:

- We accept pre-submission inquiries

- Our selector tool helps you to find the most relevant journal

- We provide round the clock customer support

- Convenient online submission

- Thorough peer review

- Inclusion in PubMed and all major indexing services

- Maximum visibility for your research

Submit your manuscript at www.biomedcentral.com/submit
Biomed Central 